\title{
EFICIÊNCIA TÉCNICA DOS PRODUTORES DE LEITE EM ASSENTADOS RURAIS DA REFORMA AGRÁRIA ${ }^{1}$
}

\author{
Samuel Alex Coelho Campos ${ }^{2}$ \\ José Ambrósio Ferreira Neto ${ }^{3}$
}

\begin{abstract}
Resumo: Este trabalho objetivou avaliar a eficiência técnica dos produtores de leite no Projeto de Assentamento (PA) Feliz União, município de Lagoa Grande, MG. Para tal, coletaram-se os dados acerca da produção de leite de 23 assentados no ano de 2007 e, posteriormente, utilizou-se, como instrumental analítico, a Análise Envoltória de Dados (DEA) para avaliar a eficiência técnica dos produtores. Os resultados obtidos mostram que a maioria dos produtores $(84 \%)$ era ineficiente tecnicamente. Dos produtores ineficientes, $87 \%$ estavam operando sob retornos crescentes a escala e $13 \%$, sob retornos decrescentes à escala. Ao analisar os eficientes e ineficientes, percebe-se principalmente que os eficientes eram mais intensivos no fator mão-de-obra e possuíam rebanho especializado para a atividade leiteira. A assistência técnica não foi um fator importante para explicar a eficiência e a ineficiência dos produtores.
\end{abstract}

Palavras-chave: Assentamentos rurais, DEA, leite, Minas Gerais.

\section{Introdução}

Os assentamentos de reforma agrária possuem grande potencial de contribuição para criação de empregos e diminuição do êxodo rural, acréscimo da oferta de alimentos, elevação do nível de renda e melhoria na qualidade de vida dos trabalhadores rurais brasileiros, como verificado por Fao (1992), e contribuem ainda, segundo Pinto (1996), para a ampliação da demanda de produtos industriais, redução na dominação

Recebido em 01/10/2008; Aceito em 29/11/2008.

2 Graduando em Gestão do Agronegócio. Universidade Federal de Viçosa, Viçosa, MG. E-mail: samuel.campos@ufv.br.

3 Doutor em Desenvolvimento, Agricultura e Sociedade. Universidade Federal Rural do Rio de Janeiro, Rio de Janeiro, RJ. E-mail: ambrosio@ufv.br. 
do poder político dos latifundiários e inserção dos assentados no processo político.

Segundo Fao (1992), Incra e Fao (1999), os assentamentos de reforma agrária dedicam-se, principalmente, às atividades agropecuárias, sendo que a produção leiteira está presente na grande maioria dos assentamentos. A produção leiteira possibilita, conforme Gomes (1997), obtenção de renda mensal, comercialização garantida e boa combinação com outras atividades da fazenda, aspectos importantes para os pequenos produtores que, geralmente, dispõem de pouco capital de giro.

Ressalta-se que o setor leiteiro brasileiro vem sofrendo transformações advindas da liberação comercial, sendo os produtores os principais atingidos. Aliado a essa situação tem-se a normativa número 51, que, segundo Gomes (2001), aprofundou o aumento de produtores atuantes no setor informal. Atualmente, o cenário de aumentos no custo de alimentação, como Carvalho (2008) destacou, eleva os custos da atividade e provoca, como destacou Moura (2005), redução nas margens de lucro ao produtor, tornando a competitividade fundamental nesse ambiente, conforme Ferreira Júnior (2004) atribuiu, na forma de eficiência técnica e alocativa dos fatores terra, trabalho e capital, objetivando a eficiência econômica e auxiliando o produtor no enfrentamento desse cenário de ameaças, com perda da margem de lucro e renda.

Esse cenário demonstra as dificuldades de permanência das famílias de pequenos produtores assentados, especialmente os que utilizam tecnologias pouco produtivas e com baixa eficiência, visto que operam custos altos, o que agrava ainda mais esse cenário quando se incluem as necessidades de investimento em tecnologia, num cenário de crédito escasso. Para que esses produtores possam enfrentar esse cenário de ameaças, tornase necessário que eles trabalhem com eficiência, para que não se utilizem recursos produtivos em excesso, mantendo, dessa forma, os custos baixos. Diante de tal realidade, surge a indagação: Os produtores assentados estão sendo eficientes na produção de leite? 


\section{Objetivos}

Este trabalho objetivou analisar a eficiência técnica dos produtores de leite nos assentamentos rurais de reforma agrária.

Os objetivos específicos foram:

1) Classificar os produtores segundo as medidas de eficiência técnica;

2) Caracterizar os produtores eficientes segundo indicadores zootécnicos de produção, os quais que permitam comparação entre os produtores eficientes e ineficientes.

\section{Referencial Teórico}

Um agente econômico que utiliza insumos para transformá-los em produtos, segundo Santos et al. (2005), está sujeito a restrições econômica, financeira e técnica. A combinação ótima de insumos, que permita obter a máxima produtividade dos insumos, é definida por Pascual (2000) como eficiência.

Para Nogueira (2005) dada a importância do conceito de função de produção para o conceito de eficiência, houve diversas tentativas de tratar eficiência a partir do conhecimento prévio da função de produção, já que esta é a expressão matemática da relação entre insumos e produtos. Debreu (1951) propôs uma definição de medida de eficiência com base na relação de distâncias, denominada por ele de "coeficiente de utilização de recursos", quantificando a proporção em que a situação obtida se distancia da ótima, considerada uma situação impossível de aumentar a satisfação de algum indivíduo, sem ao menos diminuir a de outro.

Na definição de Pareto-Koopmans e Debreu, Farrel (1957) incluiu um componente que refletisse a habilidade dos produtores em optarem por uma combinação input-output, qual seja, a eficiência alocativa, delimitando, 
assim, a eficiência em técnica e alocativa, o que possibilitou determinar a eficiência nos casos em que a função de produção não for conhecida.

A formulação de problemas de medidas de eficiência como problemas de programação linear foi concebida, pela primeira vez, por Boles, Bressler, Seitz e Sitorus, em 1966, para o caso linear das partes, segundo Färe et al., citados por Lins e Mesa (2000). Entretanto, segundo esses mesmos autores, foi com o empenho de Charnes e Cooper que os modelos DEA ganharam maior penetração a partir do modelo original CCR (sigla para Charnes, Cooper e Rhodes). Nas ciências agrárias, a DEA tem sido utilizada, entre outros estudos, na mensuração da eficiência técnica na produção leiteira, como em Gomes (1999), Ferreira (2002), Ferreira Júnior (2004), Santos et al. (2005), Jaforullah e Whiteman (1998) e Cloutier e Rowley (1993), entre outros.

Gomes (1999) utilizou a DEA para comparar os produtores de leite no Brasil por meio de indicadores técnicos e econômicos, classificando-os em eficientes e ineficientes, segundo recursos disponíveis, perfil tecnológico e resultados alcançados. Por fim, o autor simulou os impactos das transformações da produção de leite no número de produtores e requerimentos de mão-de-obra e capital.

A DEA foi também utilizada por Ferreira (2002) e Ferreira Júnior (2004), como forma de avaliar a eficiência de diferentes sistemas de produção quanto ao grau de sangue do rebanho bovino. Ferreira (2002), em sua pesquisa, ao analisar o longo e o curto prazo, verificou que 48,6 e 14,3 obtiveram medida de eficiência igual a 100 e superior a 90 no curto e longo prazo, respectivamente. A DEA foi utilizada por Santos et al. (2005), como forma de avaliar a eficiência técnica de produtores da microrregião de Viçosa, Minas Gerais, no período de 1999 a 2002. Esses autores, em seu trabalho, observaram que havia homogeneização das propriedades, em relação às características de produção atribuída ao padrão de assistência técnica oferecida aos produtores participantes.

Esse instrumental analítico tem sido utilizado também, como mensuração da eficiência, na agropecuária brasileira, como em Araújo e Carmona 
(2007); na análise da eficiência da gestão do transporte urbano por ônibus brasileiros, em Azambuja (2002); na mensuração de cooperativas de laticínios (FERREIRA, 2005); na mensuração da eficiência produtiva agrícola no estado de São Paulo (VICENTE, 1997); na eficiência em escolas municipais da cidade do Rio Grande do Sul (MOITA, 1995); e em eleições (GREEN et al., 1996).

\section{Modelo Analítico}

As fronteiras de produção podem ser estimadas de várias maneiras; neste trabalho, a determinação da fronteira eficiente de produção será feita mediante a técnica Data Envelopment Analysis (DEA). A Análise Envoltória de Dados é um método não-paramétrico desenvolvido inicialmente por Charnes et al. (1978), que estenderam a análise de eficiência de um único produto e um único insumo para a situação de múltiplos produtos e insumos (NOGUEIRA, 2005, p. 26.). Uma pressuposição fundamental na técnica DEA é que, se dada firma A fosse capaz de produzir $\mathrm{Y}(\mathrm{A})$ unidades de produtos, utilizando-se $\mathrm{X}(\mathrm{A})$ unidades de insumos, outras firmas poderiam também fazer o mesmo, caso elas estivessem operando eficientemente. De forma similar, se uma firma $B$ fosse capaz de produzir $\mathrm{Y}(\mathrm{B})$ unidades de produto, utilizando-se $\mathrm{X}(\mathrm{B})$ de insumos, então outras firmas poderiam ser capazes de realizar o mesmo esquema de produção.

Charnes e Cooper (1985) enfatizaram a necessidade de tratar a eficiência como um conceito relativo, já que a eficiência de $100 \%$ só é atingida quando comparações com outras DMUs não evidenciam a ineficiência no uso de qualquer input ou output.

No cálculo da eficiência das DMUs podem-se utilizar o modelo chamado CCR (Retorno Constante à Escala) e o modelo BCC ou VRS (Retornos Variáveis à Escala). É importante apresentar o modelo BCC junto com o modelo CCR, para que se determinam a eficiência de escala e os fatores que influenciaram essa ineficiência, sendo importante destacar que o 
modelo CCR capta ineficiências advindas da ineficiência de escala, ao contrário do modelo BCC, o que torna os scores do modelo BCC superiores aos do modelo CCR.

\subsection{Modelo com retorno constante à escala (CCR)}

Considera-se que haja $n$ DMUs e cada uma delas utilize $k$ insumos e produza $m$ produtos. São construídas duas matrizes: a matriz $X$ de insumos, de dimensões ( $\mathrm{k} \times \mathrm{n})$, e a matriz Y de produtos, de dimensões ( $\mathrm{m} \times \mathrm{n})$, que representam os dados de todas as $n$ DMUs.

$$
X=\left[\begin{array}{cccc}
x_{11} & x_{12} & \ldots & x_{1 n} \\
x_{21} & x_{22} & \ldots & x_{2 n} \\
\vdots & \ldots & \ddots & \vdots \\
x_{k 1} & x_{k 2} & \ldots & x_{k n}
\end{array}\right] \quad Y=\left[\begin{array}{cccc}
y_{11} & y_{12} & \ldots & y_{1 n} \\
y_{21} & y_{22} & \ldots & y_{2 n} \\
\vdots & \ldots & \ddots & \vdots \\
k_{m 1} & y_{m 2} & \ldots & y_{m n}
\end{array}\right]
$$

Na matriz X, cada linha representa um insumo e cada coluna, uma DMU. Na matriz Y, cada linha representa um produto e cada coluna, uma DMU. Gomes (1998) salientou que, para a matriz X, os níveis de uso de insumos são não-negativos e cada linha e cada coluna contêm, pelo menos, um nível de insumo positivo, isto é, cada DMU consome ao menos um insumo, e cada insumo é consumido por pelo menos uma firma.

De forma semelhante, para a matriz Y, os níveis de produção são nãonegativos, ou seja, cada produto é produzido por uma DMU, pelo menos, e cada DMU produz pelo menos um produto. Assim, para a i-ésima DMU, são representados os vetores $x_{i}$ e $y_{i}$, respectivamente, para insumo e produto.

Para cada DMU, pode-se obter uma medida de eficiência, que é a razão entre todos os produtos e todos os insumos. Para a i-ésima DMU, temse a seguinte medida de eficiência: 
$\mathrm{i}=\frac{u^{\prime} y_{i}}{v^{\prime} x_{i}}=\frac{\left(u_{i} y_{1 i}+\ldots u m y_{m i}\right)}{\left(v_{i} x_{1 i}+\ldots u_{k} x_{k i}\right)}$,

em que $u$ é um vetor ( $\mathrm{m} \times 1$ ) de pesos nos produtos e $v$, um vetor de pesos nos insumos.

Segundo Gomes (1999), para selecionar os pesos ótimos para cada DMU, especifica-se um problema de programação matemática. Para a i-ésima DMU, tem-se:

$\operatorname{Max} u, v\left(\frac{u^{\prime} y_{i}}{v^{\prime} x_{i}}\right)$

Sujeito a: $\left(\frac{u^{\prime} y_{j}}{v^{\prime} x_{j}}\right) \leq 1, \mathrm{j}=1,2, \ldots, \mathrm{n}$.

$u, v \geq 0$.

Na análise do DEA, o modelo linear deve ser aplicado a cada DMU, para obter, uma a uma, as medidas de eficiência. Entretanto, como a maioria das restrições é a mesma para cada problema, a obtenção da solução torna-se mais rápida. Caso a eficiência obtida para a DMU que esteja sendo testada seja igual a um, ela será eficiente em relação às demais; caso contrário, ineficiente.

Pela dualidade em programação linear, pode-se chegar a um modelo dual da formulação linearizada, da seguinte forma:

$\operatorname{Min}_{\theta, \lambda \theta}$,

sujeito a:

$-y i+\mathrm{Y} \lambda \geq 0$, 
$\theta$ xi $-\mathrm{X} \lambda \geq 0$

$\lambda \geq 0$,

em que $\theta$ é um escalar (escore de eficiência da orientação insumo), cujo valor é a medida de eficiência da i-ésima DMU. Se for igual a um, a DMU será eficiente; caso contrário, ineficiente.

O parâmetro $\lambda$ é um vetor ( $\mathrm{n}$ x 1), cujos valores são calculados de maneira que se obtenha a solução ótima. Para uma propriedade eficiente, os valores de $\lambda$ serão zero; para uma propriedade ineficiente, os valores de $\lambda$ serão os pesos das propriedades que são benchmarks (GOMES, 1999, p.48).

4.2. Modelo com retorno variável à escala $(B B C)$

O modelo BCC pode ser representado da seguinte forma:

$\operatorname{Min} \theta, \lambda \theta$,

sujeito a:

$-\mathrm{yi}+\mathrm{Y} \lambda \geq 0$,

$\theta \mathrm{xi}-\mathrm{X} \lambda \geq 0$,

$\mathrm{N}_{1}, \lambda=1$

$\lambda \geq 0$,

em que $\mathrm{N}_{1}$ é um vetor ( $\mathrm{n} \times 1$ ) de números uns, sendo que as demais variáveis já foram definidas anteriormente. 
Ao analisar os modelos CCR e o BCC, podem-se definir as eficiências das firmas. Para eficiência de escala, $\mathrm{CCR}$ igual ao $\mathrm{BCC}(\mathrm{CCR}=\mathrm{BCC})$; caso sejam diferentes, a DMU apresenta ineficiência de escala; nesse caso, têm-se duas alternativas: CCR é igual ao BCC não-crescente, retornos crescentes; caso contrário, decrescente.O modelo de Análise Envoltória de Dados foi utilizado para discriminar os produtores eficientes dos não-eficientes e para determinar os retornos à escala dos produtores estudado, e os benchmarks dos produtores ineficientes, utilizando-se, para obtenção dos scores, o software EMS, versão 1.3. ${ }^{4}$

\subsection{Fontes de dados e procedimentos utilizados}

Os dados utilizados neste trabalho referem-se a produtores leiteiros do assentamento Feliz União, município de Lagoa Grande, noroeste mineiro, colhidos pela amostra aleatória representada por 23 produtores de leite entrevistados em dezembro de 2007. Neste PA, a atividade leiteira é de grande importância, sendo que aproximadamente $80 \%$ dos assentados dedicam-se à atividade, e há 52 famílias assentadas em uma área de 2.508,26 hectares. Posteriormente, foram descartados quatro questionários da amostra, por não serem consistentes. Para cada lote foram considerados, assim como em Santos et al. (2005), a quantidade anual de leite produzida (em litros), o número total de vacas, considerando em lactação e secas ( em cabeças) e ainda os gastos com alimentação do rebanho (em R $\$ /$ mês), o número de vacas lactantes (em cabeças) e o número de pessoas envolvidas (unidades/ano) no período de janeiro de 2007 a dezembro de 2007.

\footnotetext{
${ }^{4} \mathrm{O}$ programa EMS é gratuito e pode ser baixado em: http://www.wiso.uni-dortmund.de/lsfg/or/scheel/ems/
} 


\section{Resultados e Discussão}

Os resultados serão apresentados e discutidos em três seções. $\mathrm{Na}$ primeira, são apresentados os resultados obtidos nos modelos em que se classificam os produtores em ineficientes e eficientes; na segunda, é feita uma análise agregada dos produtores eficientes e ineficientes; e, na última, é feita uma análise entre um par de produtores selecionados.

\subsection{Classificação dos produtores segundo medidas de eficiência}

Inicialmente, foram calculadas as medidas de eficiência técnica de cada produtor, pressupondo retornos constantes à escala. Em seguida, uma restrição de convexidade foi adicionada ao modelo, possibilitando calcular os scores sob retornos variáveis a escala.

Sob a pressuposição de retornos constantes à escala, $16 \%$ dos produtores obtiveram máxima eficiência técnica, sendo que $58 \%$ da amostra obtiveram medida superior a $60 \%$. Esse padrão de comportamento assimétrico da distribuição de frequiência, inclinado para direita, também foi observado por Gomes (1999), Santos et al. (2005), Jaforullah e Whiteman (1998) e Cloutier e Rowley (1993).

O nível médio de ineficiência técnica sob retornos constantes foi de $34 \%$, o que significa que os produtores podem reduzir, em média, $34 \%$ do gasto com insumos sem comprometer o nível produtivo, ao corrigir a ineficiência na alocação dos recursos. Ressalta-se que os produtores que alcançaram máxima eficiência técnica não puderam reduzir os gastos com insumos, sem comprometer a produção. Pressupondo-se retornos variáveis, $58 \%$ da amostra obteve medida de eficiência igual a um. Ao analisar a eficiência de escala,observa-se que $16 \%$ dos produtores a alcançaram, sendo denominados eficientes quanto à escala de operação, enquanto o restante da amostra foi considerada ineficiente. 


\subsection{Análise agregada dos produtores}

$\mathrm{Na}$ análise agregada dos produtores, estes foram enquadrados em dois grupos - eficientes e ineficientes, tendo como referência o modelo de retornos constantes à escala (CCR), e posteriormente comparados segundo indicadores selecionados sintetizados na Tabela1.

Os scores dos ineficientes foram, em média, de $56 \%$, o que indica que a utilização dos insumos poderia ser reduzida em $44 \%$ sem, entretanto, modificar o nível produtivo. Os produtores eficientes quanto ao trabalho atingiram produtividade aproximadamente três vezes superior. Tanto os eficientes como os ineficientes possuíam média de $70 \%$ de vacas em lactação, considerando todo o rebanho produtivo, e exploravam a mesma quantidade de mão - de obra, entretanto, considerando a produtividade deste insumo por litro, os produtores ineficientes utilizavam mais desses insumos por litro produzido.

Tabela 1. - Comparação entre indicadores de desempenho técnicos médios dos produtores eficientes e ineficientes - PA Feliz União, 2007

\begin{tabular}{llll}
\hline Descrição & Unidades & Eficientes & Ineficientes \\
\hline Score Médio & $\%$ & $100 \%$ & $56 \%$ \\
\hline Participação na Amostra & $\%$ & $16 \%$ & $84 \%$ \\
\hline Pessoas Envolvidas & Un. & 2 & 2 \\
\hline Produtividade do Trabalho & Litros/dia/Trab. & 222,5 & 79,9 \\
\hline Recebem Assistência Técnica & $\%$ & $67 \%$ & $44 \%$ \\
\hline Vacas Lactantes & Cab. & 28 & 14 \\
\hline Vacas Secas & Cab. & 12 & 6 \\
\hline Produção de Leite & Litros/dia & 445,0 & 159,8 \\
\hline Produtividade do Rebanho & Litros/Vaca/dia & 15,89 & 11,41 \\
\hline
\end{tabular}

Fonte: Dados de pesquisa, 2007. 
Quando se analisa a eficiência de escala, nota-se que 15\% da amostra operavam no ponto ótimo, enquanto o restante não atingiu a escala ótima. Formula-se outro problema de programação linear ao impor a restrição de retornos não crescentes à escala, do qual resulta o modelo VRS ou $\mathrm{BBC}$, no qual a medida de eficiência média foi de $93 \%$, sendo que o modelo sob retornos constantes apresentou média de 63\%, sendo 30 pontos percentuais de ineficiência relacionados com escala incorreta de operação, conforme Nogueira (1996) ${ }^{5}$. Com base no modelo relativo à suposição de retornos variáveis, o menor score para a eficiência técnica foi de 0,63 , sendo que $78 \%$ da amostra possuíam o coeficiente de eficiência maior que 0,9 , tornando a assimetria da amostra maior. Essa assimetria ainda maior no modelo VRS advém do fato de este não considerar a existência de ineficiências de escala.

A seguir, os produtores são separados por escala em retornos crescentes, decrescentes e eficientes, a fim de permitir a análise de algumas variáveis produtivas e níveis de retorno.

Tabela 2. - Indicadores técnicos de desempenho médios para os produtores assentados separados por escala de operação PA, Feliz União, 2007

\begin{tabular}{lllll}
\hline Descrição & Unidades & Ret. Crescentes & Eficientes & Ret. Decrescentes \\
\hline Score médio & $\%$ & $56 \%$ & $100 \%$ & $91 \%$ \\
\hline Participação na amostra & $\%$ & $74 \%$ & $16 \%$ & $11 \%$ \\
\hline Pessoas envolvidas & Un. & 2 & 2 & 3,0 \\
\hline Produtividade do trabalho & L/dia/Trab. & 58,36 & 194,72 & 175,00 \\
\hline Recebem assistência & $\%$ & $50 \%$ & $67 \%$ & $50 \%$ \\
\hline Vacas lactantes & Cab. & $12-75 \%$ & $28-70 \%$ & $36-65 \%$ \\
\hline Vacas secas & Cab. & $4-25 \%$ & $12-30 \%$ & $19-35 \%$ \\
\hline Produção de leite & Litros/dia & 119,07 & 445,00 & 525,00 \\
\hline Produtividade do rebanho & Litros/Vaca/dia & 8,64 & 16,29 & 14,69 \\
\hline
\end{tabular}

Fonte: Dados da pesquisa, 2007.

Quando se analisa a participação dos produtores que operavam sob retornos decrescentes (Tabela 2), percebe-se que havia pequena

5 A ineficiência de escala pode ser obtida pela subtração do score obtido no modelo BCC pelo CRS, segundo Nogueira (1996). 
participação na amostra; resultados semelhantes foram obtidos por Santos et al. (2005), Jaforullah e Whiteman (1998) e Gomes (1999).

A operação a níveis de retornos decrescentes indica que produziam acima do ponto tido como ótimo. Pela Tabela 2, percebe-se que os produtores sob retornos decrescentes possuíam a maior produção absoluta, entretanto, apresentavam produtividades inferiores, tanto quanto se consideram os produtores eficientes como os ineficientes, que produziam a retornos crescentes.

Nota-se que $74 \%$ dos produtores da amostra operavam abaixo da escala ótima, produção que poderia ser aumentada a custos decrescentes. Gomes (1999) verificou que interpretações de variações na escala de produção não levam em consideração mudanças tecnológicas do produtor. Esse mesmo autor citou trabalhos de SEBRAE-MG/FAEMG (1996) e Gomes (1996), que comprovam que variações no volume de produção são acompanhadas por mudanças tecnológicas. Os produtores que operavam abaixo da escala ótima estavam subutilizando seus recursos, uma vez que utilizavam a mesma quantidade de mão-de-obra, mas obtinham produtividade do trabalho e do rebanho inferior à dos produtores eficientes.

Pelos dados coletados na pesquisa, a maioria dos produtores que operavam abaixo da escala ótima fornecia concentrado e pasto como alimentação para o rebanho, descartando a hipótese de que essa baixa produtividade observada advinha da qualidade da alimentação, o que sugere que a baixa capacidade de resposta dos animais à alimentação possa ser fator importante. De fato, é o que se verifica quando se analisa a composição racial do rebanho dos produtores participantes da pesquisa. Todos os produtores eficientes possuíam rebanho especializado para a produção leiteira (raça holandesa), ao contrário dos ineficientes, que possuíam rebanho sem raça definida (mestiços). A assistência técnica, prestada no caso pela Emater, não foi fator relevante para determinação da eficiência dos produtores, o que pode ser interpretado de algumas maneiras. A primeira hipótese que emerge se refere à qualidade das informações disponibilizadas ao produtor; segundo, a eficácia da comunicação entre o produtor e o extensionista; e, por último, à 
necessidade percebida pelos produtores do conhecimento disponibilizado acerca da atividade, já que poderia haver carência de informações em algumas áreas, como visto por SEBRAE-MG/FAEMG (2005). Ressaltase que os dados da Tabela 2 devem ser interpretados com cautela, dada a amplitude entre os máximos e os mínimos observados. Gomes (1999) ressaltou ainda que a escala ótima diferia para cada produtor, em virtude de sua configuração particular de insumos e produtos.

\subsection{Comparação de pares}

O modelo permite detectar os produtores eficientes que foram os responsáveis pelo fato de determinado produtor ter sido considerado ineficiente. Nesse sentido, a medida de eficiência, obtida para cada produtor, ocorre de forma comparativa, isto é, um produtor era considerado ineficiente somente se existisse ao menos outro produtor, ou combinação de produtores, que utilizava, de forma mais racional, os insumos e produziam, no mínimo, a mesma quantidade de produto.

Esses produtores eficientes são denominados pares ou benchmarks dos ineficientes, pois figuram como referência para obtenção da medida de eficiência desses últimos. Assim, a DEA não mede somente a eficiência, mas também provê um guia para os produtores eliminarem ineficiência, onde o produtor ineficiente pode ter como referência seus pares para aumentar a sua eficiência produtiva. Como demonstração, realizou-se um estudo de caso, comparando-se um produtor ineficiente com seu respectivo par. Para selecionar os produtores adotaram-se alguns critérios, quais sejam, os produtores foram escolhidos de acordo com o maior número de produtores ineficientes que o consideraram como benchmarks, segundo o modelo CRS; a escolha dos produtores ineficientes baseou-se na obtenção de um produtor no mesmo estrato produtivo (em litros/mês) e cuja medida de eficiência técnica fosse a menor possível. Na Tabela 3 encontram-se alguns indicadores que medem o desempenho técnico dos produtores selecionados, a fim de compará-los, sendo o produtor eficiente denominado por " $\mathrm{A}$ " e o produtor ineficiente, denominado por " $\mathrm{B}$ ". 
O produtor "A" foi par de $100 \%$ dos produtores ineficientes sob a pressuposição CRS; dentre esses produtores, selecionou-se o produtor "B", que obteve medida de eficiência técnica de $56,58 \%$, o que indica que o produtor poderia reduzir a utilização de seus insumos em 43,42\% e ainda produzir a mesma quantidade de produto com a retirada da fonte de ineficiência. Convém mencionar que o produtor "B" operava sob retornos decrescentes.

Apesar de os produtores "A" e "B" encontrarem-se em mesmo nível de produtividade, as relações do tipo insumo/produto eram maiores para "A". O produtor "A" produzia 275 litros/dia a cada trabalhador envolvido na atividade, enquanto o produtor "B" produzia apenas 183 litros/dia/ trabalhador, ou seja, "A" obtinha uma produtividade para a mão-de-obra de aproximadamente 1,5 vez à produtividade do produtor $\mathrm{B}$. O produtor “A" possuía $92,5 \%$ de vacas em lactação, enquanto o "B" possuía $80 \%$, ambos indicadores elevados, entretanto "B" possuía maior quantidade de vacas em lactação que "A" e obtinha uma produção idêntica.

Tabela 3. - Indicadores de desempenho técnico dos produtores selecionados - PA Feliz União, 2007

\begin{tabular}{llll}
\hline Produtor & Unidades & A (Eficiente) & B (Ineficiente) \\
\hline Score & $\%$ & $100 \%$ & $88 \%$ \\
\hline Nat. dos retornos & $\ldots$ & Eficiência de Escala & Ret. Decrescente \\
\hline Pessoas envolvidas & Un. & 2 & 3 \\
\hline Produtividade do trabalho & Litros/dia/Trab. & 275,00 & 183,33 \\
\hline Assistência técnica & $\ldots$ & Não & Sim \\
\hline Alimentação do rebanho & $\ldots$ & Pasto e Concentrado & $\begin{array}{l}\text { Concentrado, Silagem } \\
\text { e Pasto }\end{array}$ \\
\hline Vacas lactantes & Un. & 37 & 40 \\
\hline Vacas secas & Un. & 3 & 10 \\
\hline Produção & Litros/dia & 550 & 550 \\
\hline Produtividade do rebanho & Litros/dia/vaca & 14,9 & 13,8 \\
\hline
\end{tabular}

Fonte: Dados de pesquisa, 2007. 
Pela Tabela 3, pode-se perceber que o produtor "B" fornecia aparentemente, melhor alimentação que o produtor " $A$ " ", uma vez que, além de pasto e concentrado como "A", fornecia também silagem. Entretanto, obtinha produtividade inferior. Fatores que chamam atenção é a utilização de assistência técnica por parte do produtor ineficiente e a não utilização pelo produtor eficiente, e vários são os fatores que podem explicar essa discrepância; a escolaridade é, sem dúvida, um destes. Enquanto o produtor " $A$ " havia estudado até a $4^{a}$ série, o produtor " $B$ " havia cursado apenas a $1^{\mathrm{a}}$ série, havendo superioridade no nível educacional médio entre as famílias, já que no grupo familiar do produtor "A" havia um membro que estudara até o ensino superior (superior incompleto). Apesar de a escolaridade ser importante na gestão eficiente dos lotes pelos assentados, não se pode determinar claramente, por meio deste estudo, qual o seu nível de importância na eficácia da assistência técnica e sobre a eficiência técnica dos assentados.

\section{Conclusão}

Os resultados indicam que, sob o pressuposto de retornos constantes à escala, $16 \%$ dos produtores assentados obtiveram eficiência técnica máxima. O restante da amostra foi considerada ineficiente, ou seja, os produtores poderiam reduzir o uso de insumos, sem que isso implicasse redução na produção, o que não poderia ser feito por parte dos produtores eficientes. Com relação à escala de operação, $16 \%$ da amostra operavam com eficiência de escala; $11 \%$, com retornos decrescentes à escala; e o restante, $73 \%$, com retornos crescentes e, portanto, a custos médios decrescentes.

Percebe-se que os produtores eficientes eram mais intensivos no uso do fator trabalho. Aos produtores ineficientes deveria ser disponibilizado maior acesso a cursos e treinamentos, para que estes não subutilizassem ou superutilizassem a sua capacidade produtiva e aumentassem a renda

$\overline{6}$ Os gastos com concentrado eram semelhantes para ambos, bem como a área destinada ao rebanho, de acordo com pesquisa de campo realizada. 
via aumento de receita e redução de custos. A ineficiência de alguns produtores poderia ser explicada ainda por fatores não captados pelo modelo, como a variabilidade do solo dentro de um mesmo assentamento, a disponibilidade e o tipo de fonte d'água, as experiências anteriores dos assentados, etc.

Um aspecto que chamou a atenção, nesta pesquisa, foi a desvinculação entre eficiência e assistência técnica. Tendo em vista esse fato, propõemse estudos específicos a respeito da assistência técnica neste mesmo PA. Um fator que pode explicar a desvinculação entre assistência técnica e eficiência pode ser interpretado como as dificuldades dos produtores em compreender as orientações e o fornecimento destas em desacordo com as necessidades percebidas pelos produtores, etc. Hipótese para a ineficiência da assistência técnica pode estar relacionada com a escolaridade dos produtores, como a situação demonstrada no estudo de caso, na qual um produtor com maior escolaridade obteve níveis de eficiência superiores ao que recebia assistência técnica e possuía menor nível de escolaridade. Sugerem-se pesquisas posteriores que objetivem compreender a relação entre a capacidade da assistência técnica em orientar efetivamente os produtores e o nível de escolaridade destes, com vistas em possibilitar mecanismos eficientes para a extensão.

\section{Referências}

ALVES, E. Medidas de eficiência na produção de leite. Revista Brasileira de Economia, Rio de Janeiro, v. 52, n. 1, p. 145-168, 1998.

ARAÚJO, P.M.Q.; CARMONA, C.U.M. Eficiência de uma rede de agências bancárias utilizando o modelo Data Envelopment Analysis (DEA). Disponível em <http://www.angelfire.com/va3/aco10/tgp02.pdf>. Acesso em: 30 nov. 2007.

AZAMBUJA, A.M.V. Análise de eficiência na gestão do transporte urbano por ônibus em municípios brasileiro. 2002. 385 f. Tese 
(Doutorado em Engenharia de Produção) - Universidade Federal de Santa Catarina, Florianópolis.

CARVALHO, G. Custos devem reduzir lucro. Revista Balde Branco, v. 43, n. 520, p. 11-14, fev. 2008.

CLOUTIER, L.M., ROWLEY, R. Relative technical efficiency : data envelopment analysis and Quebec's dairy farms. Canadian Journal of Agricultural Economics, v. 41, n. 2, p. 169-176, 1993.

FAO. Principais indicadores sócio-econômicos dos assentamentos de reforma agrária; versão resumida do relatório final do projeto BRA 87/022. Brasília : FAO/PNUD-MAARA, 1992. 24p.

FERREIRA, A.H. Eficiência de sistemas de produção de leite: uma aplicação da análise envoltória de dados na tomada de decisão. 2002. 120 f. Tese (Mestrado em Economia Aplicada) - Universidade Federal de Viçosa.

FERREIRA, M.A.M. Eficiência das cooperativas na indústria de laticínios. 2005. 158 f. Tese (Doutorado em Economia Aplicada) Universidade Federal de Viçosa, Viçosa.

FERREIRA JÚNIOR, S., CUNHA, N.R.S. Eficiência técnica na atividade leiteira de Minas Gerais: um estudo a partir de três sistemas de produção. Organizações Rurais e Agroindustriais, Lavras, v. 6, n. 2, p. 47-60, 2004.

GOMES, A. P. Impactos das transformações da produção de leite no número de produtores e requerimentos de mão de obra e capital. 1996. 161 f. Tese (Doutorado em Economia Rural) Universidade Federal de Viçosa, Viçosa.

GOMES, S.T. Diagnóstico e perspectivas da produção de leite no Brasil. In: VILELA, D., BRESSAN, M., CUNHA, A.S. (Eds) Restrições técnicas, econômicas e institucionais ao desenvolvimento da 
cadeia produtiva do leite no Brasil. Juiz de Fora: EMBRAPA CNPGL. 1999. 19-35p.

GOMES, S.T. Evolução recente e perspectivas da produção de leite no Brasil. In: GOMES, A.T.; LEITE, J.L.B., CARNEIRO, A.V. (Ed.). O agronegócio do leite no Brasil. Juiz de Fora: EMBRAPA/ CNPGL, 2001.207-240p.

INCRA - INSTITUTO NACIONAL DE COLONIZAÇÃO E REFORMA AGRÁRIA, FAO- Principais fatores que afetam o desenvolvimento dos assentamentos de reforma agrária no Brasil. Brasília: 1999. 62p.

JAFORULLAH, M., WHITEMAN, J.L. Scale efficiency in the New Zeland dairy industry: a non-paramentric approach. Clayton, Australia. Monash University, 1998. 16p (General Paper G-129)

LINS, M.P.S., MEZA, L.A. Análise envoltória de dados e perspectivas de integração no ambiente do apoio à decisão. Rio de Janeiro: COPPE/UFRJ, 2000, 232p.

MOURA, A. D. Et al. A produção orgânica como fonte de renda para a pequena agricultura familiar. In. MOURA, A.D. et al (Ed.). Agricultura familiar no agronegócio. Viçosa: Suprema Gráfica Editora, 2005, 107-118p.

NOGUEIRA, M.A. Eficiência técnica na agropecuária das microrregiões brasileiras. 1996. 80 f. Tese (Doutorado em Economia Aplicada) - Universidade Federal de Viçosa, Viçosa.

PINTO, L.C.G. Reforma agrária no Brasil: Esboço de um balanço. In: TEIXEIRA, E.C.; VIEIRA, W.C. (Ed.). Reforma da política agrícola e abertura econômica. Viçosa: 1996. 51-86p.

SANTOS, J. A. dos et al. Eficiência técnica em propriedades leiteiras da microrregião de Viçosa-MG: uma análise não-paramétrica. Organizações Rurais e Agroindustriais, Lavras, v. 7, n. 2, p. 162-172, 2005. 
Abstract: This paper aimed to evaluate the technical efficiency of milk producers in the Projeto de Assentamento (PA) Feliz União, municipality of Lagoa Grande, MG. To this collected data to some of the milk production of 23 settlers in 2007 and later was used as analytical tools used Data Envelopment Analysis (DEA) to assess the technical efficiency of producers. The results show that the majority of producers $(84 \%)$ are technically inefficient. Of inefficient farmers, $87 \%$ are operating under increasing returns to scale and $13 \%$ operating under diminishing returns to scale. Analyzing it is efficient and inefficient producers are mainly realizes that efficient producers are more intensive factor in the labor force and have herd dairy specialist for the activity. Technical assistance was not an important factor that explains the efficiency and inefficiency of producers.

Keywords: Rural settlement, DEA, milk, Minas Gerais.

\section{Anexo}

\begin{tabular}{|c|c|c|c|c|}
\hline \multirow{2}{*}{ Produtores } & Ret. Constante & Ret. não-crescente & Ret. Variável & \multirow{2}{*}{ Natureza dos Retornos } \\
\hline & Score & Score & Score & \\
\hline $\mathrm{F} 1$ & $41,90 \%$ & $41,90 \%$ & $63,15 \%$ & Ret. Crescente \\
\hline $\mathrm{F} 2$ & $67,24 \%$ & $67,24 \%$ & $74,87 \%$ & Ret. Crescente \\
\hline F3 & $100,00 \%$ & $100,00 \%$ & $100,00 \%$ & Eficiência de Escala \\
\hline $\mathrm{F} 4$ & $97,05 \%$ & $97,05 \%$ & $100,00 \%$ & Ret. Crescente \\
\hline F5 & $23,27 \%$ & $23,27 \%$ & $100,00 \%$ & Ret. Crescente \\
\hline F6 & $88,34 \%$ & $92,50 \%$ & $92,50 \%$ & Ret. Decrescente \\
\hline F7 & $100,00 \%$ & $100,00 \%$ & $100,00 \%$ & Eficiência de Escala \\
\hline F8 & $6,16 \%$ & $6,16 \%$ & $100,00 \%$ & Ret. Crescente \\
\hline F9 & $50,79 \%$ & $50,79 \%$ & $74,00 \%$ & Ret. Crescente \\
\hline F10 & $76,66 \%$ & $76,66 \%$ & $100,00 \%$ & Ret. Crescente \\
\hline F11 & $55,79 \%$ & $55,79 \%$ & $100,00 \%$ & Ret. Crescente \\
\hline F12 & $85,56 \%$ & $85,56 \%$ & $96,29 \%$ & Ret. Crescente \\
\hline F13 & $33,64 \%$ & $33,64 \%$ & $100,00 \%$ & Ret. Crescente \\
\hline F14 & $66,71 \%$ & $66,71 \%$ & $78,68 \%$ & Ret. Crescente \\
\hline F15 & $100,00 \%$ & $100,00 \%$ & $100,00 \%$ & Eficiência de Escala \\
\hline F16 & $78,72 \%$ & $78,72 \%$ & $90,17 \%$ & Ret. Crescente \\
\hline F17 & $54,55 \%$ & $54,55 \%$ & $100,00 \%$ & Ret. Crescente \\
\hline F18 & $93,71 \%$ & $94,04 \%$ & $94,04 \%$ & Ret. Decrescente \\
\hline F19 & $40,20 \%$ & $40,20 \%$ & $100,00 \%$ & Ret. Crescente \\
\hline
\end{tabular}

